\title{
O PLANEJAMENTO E A UTILIZAÇÃO DOS PLANOS DE AULA "NOVA ESCOLA" EM MATEMÁTICA
}

\author{
PLANNING AND USING "NEW SCHOOL" CLASS SCHEMES IN \\ MATHEMATICS
}

\author{
Rosiane Figueredo Prates ${ }^{1}$ \\ Adriana da Costa Barbosa ${ }^{2}$
}

\begin{abstract}
Resumo: Esse estudo descreve o processo de planejamento de aula, a partir da análise de metodologia no contexto do Projeto Planos de Aula "Nova Escola" para a unidade de Números elencado na Base Nacional Comum Curricular - BNCC. O percurso metodológico perpassa a reflexão dos pressupostos sobre planejamento escolar, organização didática da aula, planejamento de ensino, bem como a análise da aprendizagem sob a ótica de uma matemática criativa. Os pressupostos pedagógicos e metodológicos ampararam a reflexão da metodologia contida nos planos de aulas, sua relação com o planejamento docente e o processo de ensino-aprendizagem em Matemática no Ensino Fundamental, nos ajudando a compreender um planejamento de matemática realizado no contexto da revista "Nova Escola". Esperamos que este estudo possa contribuir para reflexão acerca do planejamento nas aulas de matemática, a fim de que o ensino da disciplina possa ocorrer de maneira diferenciada e atrativa.
\end{abstract}

Palavras-chave: Planejamento; Ensino; Matemática; Plano de Aula; Nova Escola.

\begin{abstract}
This study describes the lesson planning process, from the analysis of methodology in the context of the "Nova Escola" Lesson Plans Project for the Numbers unit listed in the National Common Curricular Base - BNCC. The methodological path runs through the reflection of the assumptions about school planning, the didactic organization, the teaching planning, as well as the analysis of learning from the perspective of creative mathematics The pedagogical and methodological assumptions, supported the reflection of the methodology contained in the lesson plans, its relationship with the teaching planning and the teaching-learning process in Mathematics in Elementary School, helping us to understand a mathematical planning carried out in the context of the "Nova Escola" magazine. We hope that this study can contribute to reflection about planning in mathematics classes, so that the teaching of the discipline can occur in a different and attractive way.
\end{abstract}

Keywords: Planning; Teaching; Mathematics; Class Plan; Nova Escola.

\footnotetext{
${ }^{1}$ Especialista em Educação: Currículo e Ensino. Instituto Federal do Espírito Santo (IFES). Docente da Rede Municipal de Educação, Pinheiros, ES, Brasil. Participante do Time de Autores no projeto Planos de Aula NOVA ESCOLA - componente Matemática. pratesdocencia@gmail.com

${ }^{2}$ Mestre em Informática, Universidade Federal do Espírito Santo (UFES). Docente do Instituto Federal de Educação, Ciência e Tecnologia do Espírito Santo e participante do grupo de pesquisa em Educação Matemática e Educação Profissional (EMEP), Vitória, ES, Brasil. acbifes@ gmail.com
} 


\section{Introdução}

DOI:10.33238/ReBECEM.2020.v.4.n.3.25262

Quando o processo de ensino-aprendizagem é considerado em Matemática, em especial no Ensino Fundamental, observamos que os resultados de tal processo possui relação direta com o tipo de metodologia utilizada, ou seja, com a definição do planejamento docente, uma vez que diversos aspectos precisam ser considerados, como nível cognitivo dos alunos, proposta curricular e de avaliação, objetivos pré-fixados, tipo de atividade a ser utilizada e recursos disponíveis.

Ao considerar o processo de ensino-aprendizagem no contexto da proposta do currículo, educação e ensino, são notáveis os diversos desafios que podem interferir no processo de planejamento, uma vez que Haydt (2006, p.102), considera que "[...] no planejamento de aula, o professor especifica e operacionaliza os procedimentos diários, para a concretização dos planos de curso e de unidade". Dessa maneira, tem-se como objetivo principal desse estudo refletir sobre o processo metodológico de elaboração de planos de aula no contexto do Projeto de Aula "Nova Escola" de conteúdos de Matemática à luz do processo cognitivo do esforço produtivo. De forma específica, esse objetivo divide-se em refletir sobre metodologia contida no processo de elaboração dos planos, apresentar o processo cognitivo do esforço produtivo e analisar a contribuição desse modelo de planejamento na proposta docente.

Todos esses aspectos foram observados pela prática pedagógica, em séries de $6^{\circ}$ ao $9^{\circ}$ ano, na disciplina de Matemática buscando compreender o processo de ensino e aprendizagem, com foco na relação existente entre proposta curricular, métodos de ensino e metodologias utilizadas. Durante nosso percurso profissional aliado à nossa formação acadêmica.

Algumas ideias ligadas à realização de aulas diferenciadas fortaleceu o início de ações ligadas ao projeto de aprendizagem, buscando aproximar a Matemática ao cotidiano do aluno, uma vez que “[...] entre a teoria e prática persiste uma relação dialética que leva o indivíduo a partir para a prática equipado com uma teoria e a praticar de acordo com essa teoria até atingir os resultados desejados." (D’AMBROSIO, 1996. p.79). Assim, o desejo em fixar estratégias voltadas à disseminação de um ensino de Matemática diferenciado, fundamentado em ações voltadas a uma aprendizagem colaborativa, onde o aluno torna-se protagonista nesse processo de ensino e aprendizagem, tornou-se mais evidente na nossa prática docente. Pode-se afirmar ainda que tais aspectos foram fortalecidos a partir dos estudos de Libâneo (2006), que enfatizam a aula como 
DOI:10.33238/ReBECEM.2020.v.4.n.3.25262

organização do ensino, de Veiga (2008) que evidencia à organização didática da aula, e de Haydt (2006) que estuda o planejamento voltado para a ação didática.

Na descrição de Libâneo (2006, p.241), “[...] o plano de aula é a forma predominante de organização do processo de ensino", ele considera que é na aula que o professor cria situações, ou seja, condições para que os alunos consigam assimilar ativamente os conhecimentos, e assim ocorra o desenvolvimento cognitivo. É enfatizada ainda, a importância de estabelecer relação entre objetivos e conteúdos, com a finalidade de detalhar o plano de ensino, caracterizado pelo plano de aula. É possível inferir a partir do pensamento do autor, que o trabalho docente tem um aspecto significativo no processo de formação do aluno, ao considerar as diversas situações de caráter social, psicológico, ambiente escolar, presente no cotidiano, que precisam ser consideradas no âmbito do processo da avaliação, uma vez que são indicadas algumas perguntas, com objetivo de favorecer uma reflexão por parte do professor referente à sua prática, dentre elas “[...] os objetivos e técnicas foram adequados à turma? Houve uma organização segura das atividades? Os métodos e técnicas de ensino foram variados e oportunos para suscitar a atividade mental e prática dos estudantes?” (LIBÂNEO, 2006, p.241). Ao realizar uma reflexão a partir da análise das respostas dessas perguntas, é possível identificar que o docente consiga avaliar sua prática, sob um olhar fixado ao planejamento e assim consiga visualizar estratégias favoráveis às ações do cotidiano em sala.

É considerável que Veiga (2008) evidencia a importância do planejamento no ensino, da proposta curricular e suas vertentes, e da necessidade de flexibilizar o planejamento a realidade educacional do aluno, pois considera que a organização da aula precisa estar articulada ao projeto pedagógico do curso, a fim de contextualizar e orientar as atividades didáticas. Destaca-se ainda que a autora estrutura a organização didática da aula através de esquema representado a partir do levantamento de várias perguntas, como "para quê", relacionado à intenção; "para quem", com foco no aluno; “o quê", relacionado ao conteúdo; "quem" com foco no papel do professor; "como", direcionado a metodologia; "quando", relacionado ao tempo; "com o quê", relacionado aos recursos didáticos; "onde", ligado ao espaço e "o quê", "como" e "quem", relacionado a avaliação. Para Veiga (2008), é permitido por meio das respostas dessas perguntas, a articulação por parte do professor, da ação formativa, com foco nos objetivos definidos intrínsecos aos conteúdos e meios didáticos. Por fim, ela acredita que a educação pode ser considerada “[...] um encontro de projetos, que é ao mesmo tempo difícil, conflitante, angustiante, 
DOI:10.33238/ReBECEM.2020.v.4.n.3.25262

altamente provocativo, desafiador e ao mesmo tempo prazeroso." (VASCONCELOS, 1999, p.131 apud VEIGA, 2008, p.275).

Quando o planejamento da ação didática é analisado a partir do pensamento de Haydt (2006), compreendemos que planejar está relacionado à análise de uma realidade, onde a reflexão de condições existentes precisam ser consideradas, a fim de prever maneiras alternativas de superar barreiras e alcançar os objetivos fixados. Compreendese ainda, a partir da definição de planejamento de aula da autora, que a elaboração de um plano de aula, precisa considerar os conhecimentos prévios dos alunos, ou seja, o que eles já sabem, a fim de contribuir na concretização do objetivo da aula contido no planejamento das atividades didáticas, que muitas vezes causa interesse em descobrir ou fixar caminhos que norteiam resultados diferentes.

Com todos esses anseios, de contribuir positivamente com o processo de ensino em Matemática, especialmente na rede pública municipal, ocorreu oportunidade em participar do projeto Planos de Aula da revista "Nova Escola", para a elaboração de planos de aula em Matemática, dentro da unidade números, alinhados a Base Nacional Comum Curricular (BNCC) na habilidade EF07MA08 que traz a ideia de "[...] comparar e ordenar frações associadas às ideias de partes de inteiros, resultado da divisão, razão e operador", conforme descrição (BRASIL, 2017, p.305).

\begin{abstract}
O projeto Planos de Aula Nova Escola é resultado de uma parceria entre a Associação Nova Escola, que publica a Nova Escola, a Fundação Lemann, mantenedora da Associação, e o Google.org, braço filantrópico do Google. Os planos de aula de Matemática estarão disponíveis gratuitamente para todos os professores do país. O projeto Planos de Aula Nova Escola é a primeira ação em escala nacional a criar materiais online e gratuitos, para sala de aula, alinhados à Base Nacional Comum Curricular (BNCC) da Educação Infantil e do Ensino Fundamental. O objetivo do projeto é disponibilizar planejamentos, ideias de boas atividades, resoluções comentadas e referências de formação para todos os professores do Brasil, sempre com o cuidado de colocar o aluno no centro da aprendizagem. A iniciativa da Associação Nova Escola teve início em 2017, com o apoio da Fundação Lemann e do Google.org. Juntas, as organizações acreditam que o professor deve ocupar o lugar de referência como autor de conteúdo de qualidade para sala de aula (NOVA ESCOLA, 2020, n.p.).
\end{abstract}

O estudo para produção dos planos de aula ocorreu no mês de novembro do ano de 2017 no município de Itapeva - MG, no período de 02/11/17 a 05/11/2017, contabilizando uma carga horária de 25 (vinte e cinco) horas. A formação foi organizada a fim de atender cronograma de quatro dias de estudo onde ocorreram discussões sobre Matemática, Didática e Base Nacional Comum Curricular, e houve análise crítica do processo de elaboração de planos de aulas referente às áreas de Grandezas e Medidas, 
DOI:10.33238/ReBECEM.2020.v.4.n.3.25262

Álgebra, Probabilidade e Estatística, Geometria e Números. Na formação ocorreram discussões sobre Matemática, Didática e Base Nacional Comum Curricular, com foco especial no processo cognitivo do esforço produtivo em Matemática, mediante as considerações de Boaler (2018), professora pesquisadora da Universidade de Stanford (EUA) e cofundadora do YouCubed, ministrado por Katia Cristina Stocco Smole, doutora em Educação pela Faculdade de Educação da Universidade de São Paulo, na área de Ensino de Ciências e Matemática, diretora do grupo Mathema de formação e pesquisa e do Instituto Reúna, associada do Todos Pela Educação, membro do Movimento Pela Base, membro do conselho administrativo da Fundação Nova Escola, membro do conselho consultivo das revistas Pátio, atuou como Secretária de Educação Básica no MEC, membro do Conselho Nacional de Educação. Durante esse momento, pudemos refletir sobre a abordagem, sua aplicabilidade e potencialidades no desenvolvimento de habilidades intrínsecas a aprendizagem Matemática. Sendo assim, essa experiência tornou-se significativa considerando o processo formativo, acarretando em empenho e motivação para a realização de um ensino diferenciado. (DARC, 2017).

Foi identificada a necessidade de apresentar os benefícios e importância do processo de planejamento desenvolvido no projeto "Nova Escola" para o processo de ensino-aprendizagem, através da utilização dos planos de aula, a fim de instigar essa prática em outros professores. A perspectiva é de contribuir com a disseminação de um ensino público de qualidade por meio de uma reflexão acerca do esforço produtivo considerado por Boaler (2018, p.17) “[...] como uma ação positiva que provoca desafio durante aplicação e resolução de problemas nas aulas de Matemática, ocasionando assim uma análise de erros ligada ao desenvolvimento de mentalidades matemáticas que é causado a partir dessa ação".

Dessa forma, este trabalho visa descrever sobre a metodologia de elaboração de planos de aula no contexto do Projeto Planos de Aula "Nova Escola", referente aos conteúdos de Matemática, sistematizados de acordo com habilidades descritas na BNCC, dividida de acordo com as unidades temáticas de Números, Álgebra, Geometria, Grandezas e medidas, Probabilidade e Estatística, à luz do processo esforço produtivo, enfatizado por Kátia Smole, baseado no proposto de Boaler (2018). Para atingir esse objetivo geral, faz-se necessário descrever aspectos da abordagem do esforço produtivo, considerando-a como um meio para realizar "perguntas certas", a fim de levar os alunos 
DOI:10.33238/ReBECEM.2020.v.4.n.3.25262

a reflexão de como chegar à solução final, bem como identificar a aprendizagem nesse percurso de busca pela solução.

O planejamento considerando a proposta de Boaler (2018), e o esforço produtivo, resulta em dois tipos de planos de aulas: o conceitual e o de ampliação. Ambos são compostos por atividades de: aquecimento ou retomada; principal; raio x e intervenção pedagógica. A atividade de aquecimento é a introdução, revisão ou contextualização. A atividade principal refere-se ao conceito e resolução de problemas que norteará a aula. A atividade de raio x são as perguntas destinadas à relação dialética no estudo dos conceitos e na resolução de problemas. E a atividade pedagógica apresenta possibilidades de ações que podem ajudar nos momentos desafiadores.

Dessa maneira esse trabalho é descrito em seções, com temas de metodologia, ensino-aprendizagem em Matemática, prática docente, o plano de adição e subtração de racionais na prática como exemplo e considerações finais.

\section{Metodologia}

Este trabalho é fruto de uma investigação qualitativa e classifica-se como um estudo de caso, que segundo Yin (2001) tem aspectos fundamentados na busca de respostas para questões que tem como fator identificador o "como e por que". O autor destaca como aspecto diferenciador desse modelo de estudo a observação direta e a ampla variedade de evidências através de documentos, artefatos, entrevistas e observações, o que caracteriza um estudo de caso descritivo, ou seja, aquele que tem como objetivo a descrição e verificação do fenômeno estudado.

O percurso metodológico na construção desse trabalho ocorreu em três etapas. A primeira foi caracterizada pelo estudo e escolha de autores que dialogassem com a referência teórica adotada pela revista "Nova Escola", no período de formação de autores, que é Jo Boaler. Nessa etapa foi realizada a revisão de literatura, sendo possível relacionar o pensamento de Haydt (2006), referente à operalização do planejamento de aula, com o pensamento de D’Ambrósio (1996) quanto à relação dialética entre teoria e prática, enfatizado pelos estudos de Libâneo (2006) que destaca a aula como organização do ensino, de Veiga (2008) que descreve sobre a organização didática da aula, com consideração aos Parâmetros Curriculares Nacionais (PCNs) e Base Nacional Comum Curricular (BNCC). 
DOI:10.33238/ReBECEM.2020.v.4.n.3.25262

A segunda etapa consistiu na escolha de um plano de aula da revista "Nova Escola". Optou-se pelo plano adição e subtração de racionais na prática, que tem como objetivo ampliar o conceito de adição e subtração com racionais na forma fracionária, referente a habilidade EF07MA08, da Unidade Temática de Números da Base Nacional Comum Curricular. E a terceira foi a análise detalhada desse plano de aula adição e subtração de racionais fracionários na prática.

\section{Ensino- aprendizagem de Matemática}

Ao considerarmos a perspectiva do ensino em Matemática, o desempenho e formação de capacidade intelectual, é necessário considerar a estruturação do pensamento relacionada à análise e capacidade de resolver situações-problemas, pois segundo os Parâmetros Curriculares Nacionais - PCN's de Matemática

\footnotetext{
o fato de o aluno ser estimulado a questionar sua própria resposta, a questionar o problema, a transformar um dado problema numa fonte de novos problemas, evidencia uma concepção de aprendizagem não só pela mera reprodução de conhecimentos, mas pela via da ação refletida que constrói conhecimentos (BRASIL, 1997, p.45)
}

Partindo desse princípio, um ponto que precisa de atenção é referente ao uso de atividades diferenciadas por parte do docente que podem motivar a exploração de um conhecimento matemático de maneira significativa e contextualizada, uma vez que,

[...] a Matemática, não só no Brasil, é apresentada sem vínculos com problemas que fazem sentido na vida das crianças e dos adolescentes. Os aspectos mais interessantes da disciplina, como resolver problemas, discutir ideias, checar informações e ser desafiado, são pouco explorados na escola. $\mathrm{O}$ ensino se resume a regras mecânicas que ninguém sabe, nem o professor, para que servem. (SADOVSKY, 2007, p.8 apud LIMA; COELHO, SILVA, 2016, p.566)

Os estudos de Boaler (2018) estão relacionados ao ensino da Matemática. A autora acredita que a Matemática pode e precisa ser ensinada como uma disciplina criativa e visual, numa perspectiva que alia teoria à prática, em um viés envolvente e relevante com potencial para inspirar todos que acreditam no poder que a educação tem de transformar vidas. Jo Boaler é professora de educação matemática da universidade de Stanford e cofundadora do YouCubed Centro de Stanford que fornece recursos de educação matemática para professores, alunos e pais. Além disso, ela é, analista no Programa Internacional para Avaliação de Alunos (PISA), “[...] uma iniciativa de avaliação comparada, aplicada de forma amostral a estudantes matriculados a partir do $7^{\circ}$ ano do 
DOI:10.33238/ReBECEM.2020.v.4.n.3.25262

ensino fundamental na faixa etária dos 15 anos, idade em que se pressupõe o término da escolaridade básica obrigatória na maioria dos países" (INEP, 2019, n. p). A autora defende uma metodologia de planejamento a partir da descrição de atividades embasadas na dissociação entre teoria e prática, em que os alunos do Ensino Fundamental e Ensino Médio são engajados a resolver situações problemas a partir de uma proposta didática investigativa e dinâmica, planejadas com foco para uma mentalidade de crescimento. (BOALER, 2018)

Boaler (2018) enfatiza a Matemática como uma disciplina aberta, de crescimento e de aprendizagem com princípios que incentivam o desenvolvimento dentro do contexto da aprendizagem matemática. Por exemplo, pode-se encorajar os estudantes a valorizar a dificuldade e o fracasso, com a finalidade de romper o mito do "desempenho sem esforço", pode-se elogiar e ajudar os estudantes para o crescimento, pode-se ensinar a disciplina de forma aberta e visando o crescimento respeitando os padrões e conexões da disciplina enfatizando sua forma criativa e visual.

É importante destacar que a autora faz apontamentos acerca do desenvolvimento cognitivo, objetivo de estudo da neurociência e da psicologia. Nesse aspecto, ela menciona que "[...] quando aprendemos uma nova ideia, uma corrente elétrica dispara em nossos cérebros, passando por sinapses e ligando áreas cerebrais" (BOALER, 2018, p. 1), tal aspecto é evidenciado pela autora quando a aprendizagem acontece, segundo a mesma, pode ser nas salas de aula, leitura de um livro, quando conversamos, por meio de jogos e outras experiências. Ainda afirma que “[...] estudantes com mentalidade de crescimento encaram trabalhos difíceis e veem os erros como um desafio e uma motivação para fazer mais" (BOALER, 2018, p. 7) características que favorecem a continuidade na realização de tarefas, ou seja, é entendido que à medida que o aluno consegue percorrer o caminho da resolução nos diferentes níveis.

Dessa maneira, ao considerar os estudos dessa pesquisadora em Educação Matemática, identifica-se orientações valiosas para a realização do planejamento das aulas de matemática, foco de nossa pesquisa, uma vez que a autora defende a metodologia dialética, através da realização de perguntas ideais, com finalidade de incentivar o pensamento crítico do aluno e levá-lo à reflexão do seu processo de resolução de problema, caracterizando o esforço produtivo por meio desses aspectos. O professor assume papel de mediador do processo, onde o aluno é protagonista da sua ação, a partir 
DOI:10.33238/ReBECEM.2020.v.4.n.3.25262

da aplicação de atividades matemáticas produtivas com finalidade de despertar a curiosidade, por meio de desafio e colaboração.

\section{Prática Docente}

Ao considerar o processo de ensino-aprendizagem e a prática docente é necessário considerar fator integrante o planejamento, caracterizado como "[...] uma atividade que orienta a tomada de decisões da escola e dos professores em relação às situações docentes de ensino e aprendizagem, tendo em vista alcançar os melhores resultados possíveis" (LIBÂNEO, 2006, p.226). Dessa maneira, compreendemos que o planejamento é um fator indispensável no processo educativo, uma vez que vários aspectos precisam ser considerados, como a disposição curricular dos conteúdos e as condições prévias de aprendizagem dos alunos, qual metodologia é adequada de acordo com a realidade educacional, bem como se o modelo de assimilação e contextualização dos conteúdos são favoráveis ao desenvolvimento da aprendizagem, conforme objetivos pré-fixados.

Com o intuito de refletir, sobre a maneira que se pode realizar esse tipo de planejamento, é descrito a estrutura dos planos de aula que integram o Projeto Planos de Aula para a revista "Nova Escola", desenvolvidos no período de novembro do ano de 2017 a fevereiro do ano de 2018. Os planos foram produzidos de acordo com alguns parâmetros pedagógicos, o alinhamento à Base Nacional Comum Curricular, realidade da escola pública e o aluno como protagonista. A revista "Nova Escola" dispõe de 535 planos relacionados a unidade Números, 190 planos na unidade Álgebra, 270 planos na unidade de Geometria, 220 planos na unidade de Grandezas e medidas e 140 planos referente à unidade de Probabilidade e Estatística. Todos os planos são compostos por slides de apresentação, atividade para impressão com resolução e guia de intervenção pedagógica. Os planos são classificados em dois tipos, conceitual e de ampliação. O quadro 1 apresenta os elementos de cada um deles. 
DOI:10.33238/ReBECEM.2020.v.4.n.3.25262

Quadro 1: Tipos de planos de aula da Nova Escola

\begin{tabular}{|c|c|}
\hline Plano conceitual & Plano de ampliação \\
\hline Objetivo & Objetivo \\
\hline Aquecimento & Retomada \\
\hline Atividade principal & Atividade principal \\
\hline Discussão das soluções & Discussões das soluções \\
\hline Sistematização do conceito & Encerramento \\
\hline Encerramento & Raio X \\
\hline Raio X & - \\
\hline
\end{tabular}

Fonte: Nova Escola (2017)

O item objetivo, contido no plano conceitual e de ampliação, é o momento para compartilhar sobre o que se deseja na aula. No plano conceitual, o aquecimento refere-se a atividade inicial ou reflexão que expõe o aluno a conceitos já aprendidos, a atividade principal, claramente relacionada à atividade de aquecimento, visa oportunizar o aluno a aprender um novo conceito. A sistematização do conceito visa a apresentação do conceito relacionado à atividade principal.

No plano de ampliação, a retomada estabelece uma conexão com a aula conceitual, com o objetivo de apoiar os alunos a usar os conceitos-chave para entender algoritmos e procedimentos. A atividade principal tem como objetivo oportunizar a prática do conceito, aprendido anteriormente, ou resolução de problemas usando conceitos já aprendidos, com a finalidade de proporcionar ao aluno fazer conexões entre conceitos conhecidos, aplicar ou ampliar o entendimento conceitual para uma nova situação.

Quanto ao plano conceitual e ao de ampliação, a discussão das soluções tem como finalidade apresentação das diferentes soluções encontradas pela turma, costuma envolver análise de erros e dificuldades e, também contém a valorização de diferentes soluções, onde objetiva-se que cada aluno compreenda pelo menos uma resolução que leve ao resultado correto. No encerramento é demonstrado um resumo da aprendizagem em relação ao que foi explorado na aula e o raio x, refere-se à atividade para avaliação do progresso do objetivo da aprendizagem com sugestão para erros comuns, ou seja, o raio x pode ser usado como um recurso de verificação da aprendizagem, a partir da análise do objetivo da aula.

A título de ilustração, será analisado o plano intitulado Adição e subtração de racionais fracionários na prática, pensado para alunos do $7^{\circ}$ ano do Ensino Fundamental, no entanto, passível de aplicação em outras séries (NOVA ESCOLA, 2018). O plano pode 
DOI:10.33238/ReBECEM.2020.v.4.n.3.25262

ser usado como intervenção pedagógica no processo de ensino-aprendizagem referente a dificuldade dos discentes em trabalhar as quatro operações com racionais fracionários, uma vez que a descrição nesse artigo se refere a operação de adição e subtração.

\section{$5 \mathrm{O}$ processo de planejamento/criação dos planos de aulas}

Os planos de aula da disciplina de Matemática foram produzidos por um grupo de professores, denominado Time de Autores, composto por 150 professores, 30 mentores e 5 especialistas de 115 cidades, 18 estados e 5 regiões a partir de seleção externa realizada pela revista "Nova Escola". A seleção foi composta por três etapas, sendo a primeira o preenchimento de formulário contendo dados referente a formação e atuação profissional, e as demais por meio da realização de teste com questões objetivas e discursivas relacionadas à disciplina. Também foi necessário o envio de plano de aula, conforme modelo disponibilizado nas orientações do edital de seleção. O plano de aula deveria conter o conteúdo em slide, atividade modelo com resolução e guia de intervenção pedagógica.

A produção dos planos foi realizada conforme descrição das unidades temáticas e habilidades da Base Nacional Comum Curricular. O processo contou com o planejamento das unidades dos planos de aula, a elaboração, a revisão e o aprimoramento dos planos designados para garantir precisão conceitual e rubrica de qualidade. Os mentores têm o papel de parceiro do professor na construção dos planos. Eles acompanham o trabalho do professor, comentam e sugerem melhorias. Com isso, é mais provável garantir a precisão conceitual, e certificar-se que o professor cumpra prazo e padrões de qualidade, preestabelecidos de acordo com a rubrica de qualidade, e contribuir com o repertório dos professores. Já a função do especialista é fornecer referências para o trabalho do time, esclarecer dúvidas de conteúdo, assegurar a progressão da aprendizagem, fazer leituras e indicar mudanças, se necessário, transformar dúvidas e problemas em formações, contribuir com o compartilhamento de boas práticas e ideias, uma vez que todo esse processo foi realizado com foco no diálogo entre as partes, com valorização de ideias, participação e colaboração. (NOVA ESCOLA, 2020)

Importante considerar que após a finalização dos planos, foi realizada ação de verificação para checagem de padrão, considerado como aspectos pré-publicação, relacionado à estrutura do material (tamanho de slide, fonte, documentos faltantes) e 
DOI:10.33238/ReBECEM.2020.v.4.n.3.25262

gramática, com objetivo de enviar planos para o publicador, responsável por disponibilizar os planos na plataforma. (NOVA ESCOLA, 2020)

O processo está ancorado em três princípios: colaboração, impacto e desenvolvimento, pois entende-se que o grupo é considerado uma comunidade de aprendizagem com características de visão positiva do trabalho que realizam, capacidade de executar projetos comuns. Todos aprendem e desenvolvem suas habilidades, com acesso ao conhecimento e abertura para o diálogo e empatia. Após a finalização dos planos, os mesmos foram analisados por um Comitê de Qualidade, composto por integrantes da equipe "Nova Escola", da área de políticas públicas e planejamento docente de entidade parceira, da formação de professores, da coordenação pedagógica e de professores de escolas públicas e estudante de licenciatura, totalizando até então, 12 componentes. (NOVA ESCOLA, 2017)

A rubrica de qualidade dos planos tem relação direta com os pilares pedagógicos descritos pela coordenação pedagógica do Projeto, que considera que os planos estejam alinhados à Base Nacional Comum Curricular, à realidade da escola pública brasileira e que o aluno esteja no centro do processo como protagonista no processo de ensinoaprendizagem, além de considerar outros aspectos como estrutura dos planos de aula, materiais complementares, contexto social, linguagem, conceitos, nível de dificuldade, conceitos, tempo, dinâmica da aula, objetivo, avaliação e guia de intervenção. Este último tem como objetivo abordar possíveis dificuldades dos alunos, a fim de apresentar encaminhamentos que colaboram com o avanço dos estudantes, através de momentos desafiadores, por exemplo, em vez de dar pistas para o aluno, é indicado ao professor a realização de perguntas que proporcione o aluno a refletir sobre o caminho percorrido para chegar a tal resultado (NOVA ESCOLA, 2020).

\section{O plano adição e subtração de racionais fracionários na prática como exemplo}

O plano de ampliação, adição e subtração de racionais na prática, foi elaborado com foco na habilidade EF07MA08, sendo as letras maiúsculas EF indicando o nível Ensino Fundamental, 07 referente ao sétimo ano, MA indicando a disciplina de Matemática e 08, a habilidade corresponde à unidade temática de Números, que compreende o comparar e ordenar frações à ideia de partes de inteiros, resultado da divisão, razão e operador. O plano evidencia a ampliação do conceito dos números racionais fracionários dentro do cálculo de adição e subtração. É entendido que a turma 
DOI:10.33238/ReBECEM.2020.v.4.n.3.25262

deve dominar, segundo as orientações da BNCC, o conceito de fração, identificar a relação entre os conjuntos numéricos (racionais, inteiros e naturais), realizar adição e subtração com racionais, aspectos relacionados às habilidades EF06MA06; EF06MA07; EF06MA08; EF06MA09, ou seja, habilidades descritas na unidade de Números para nível de sexto ano.

Como todo planejamento são apresentados os objetivos que “[...] são formulações que derivam das intenções. São um guia para orientar o processo didático. Devem incluir as seguintes capacidades humanas: cognitivas, afetivas, psicomotoras, de relações interpessoais e de inserção social" (VEIGA, 2008, p. 276). Dessa maneira é necessário observar ainda alguns critérios elencados por Veiga (2008) que destaca a coerência interna, com fator que relaciona objetivos gerais e específicos; contextualização, que considera significativa a relevância social tanto para o aluno, quanto para o professor e adequação, com a finalidade de corresponder aos interesses e possibilidades dos alunos.

No presente plano objetiva-se ampliar o conceito de adição e subtração com racionais escritos na forma fracionária, sendo esse o conceito-chave da aula, ou seja, todo o planejamento da ação didática para essa aula está relacionado à ampliação do conceito de adição e subtração com racionais na forma fracionária. O plano é caracterizado como de ampliação, logo é um plano conceitual, sendo que o sugerido é que primeiro o aluno conheça o conceito e posteriormente amplie o mesmo, pois tal aspecto é relacionado a teoria e prática descrita por D’Ambrósio (1996).

Para a consecução desses objetivos e do conceito é preciso listar os materiais e recursos necessários ao desenvolvimento da aula, ou seja, é preciso conhecer a realidade da turma, do ponto de vista cognitivo, da escola, quanto a disponibilização dos objetos necessários, sendo importante considerar recursos acessíveis à realidade docente, pois caso uma aula seja fixada a partir de recursos de difícil acesso, fora da realidade escolar, pode ocorrer à não execução da aula de maneira desejada, aspecto que pode interferir na aprendizagem dos discentes.

No plano analisado, os recursos necessários são atividades impressas em folhas, coladas no caderno ou não, projetor multimídia (caso não se utilize impressões) ou os dois conforme disponibilização de recursos do ambiente escolar. Importante lembrar, que todos os planos de aula do Projeto Planos de Aula, foram elaborados com a finalidade de aplicação em todas as regiões do Brasil, conforme interesse do professor, a fim de contribuir positivamente com o fortalecimento de uma Educação pública e de qualidade, 
DOI:10.33238/ReBECEM.2020.v.4.n.3.25262

através da disponibilização de material didático e de apoio aos docentes das diversas redes de ensino. No entanto, é preciso alertar que os planos precisam de adaptações para o trabalho com alunos com necessidades específicas como por exemplo: baixa visão, cegueira, etc.

O primeiro slide contém o objetivo da aula, que é ampliar o conceito de adição e subtração com racionais escritos na forma fracionária, que é claro e objetivo. Existe a orientação de apresentar o objetivo da aula de maneira breve, projetar ou ler o objetivo para a turma. Recomenda-se que essa ação dure, em torno de 2 minutos.

No segundo slide (retomada), o propósito é relembrar conceitos já aprendidos e que serão necessários à aula, através de atividade. Tem como orientação ao professor, a retomada do conceito de adição e subtração com racionais fracionários negativos e positivos, fazendo uma revisão oral e coletiva. Relembrar como é feita adição e subtração quando os denominadores são diferentes e orientá-los sobre o uso dos sinais. A figura 1 apresenta o segundo slide da apresentação.

Figura 1: Slide de retomada

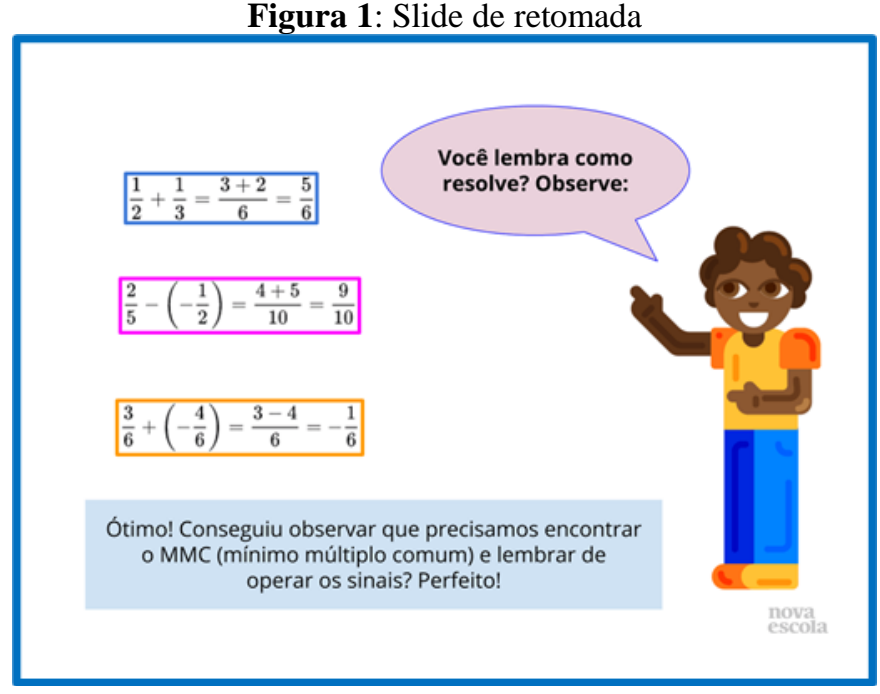

Fonte: Nova Escola (2018)

No terceiro slide (atividade principal) apresentado na figura 1, o tempo sugerido é de 18 minutos, tendo como objetivo trabalhar o contexto de adição e subtração de números racionais de maneira contextualizada, em situações próximas do cotidiano do aluno, de maneira prática e dinâmica. Tem como orientação, sugestão ao docente: separe a turma em grupos de 3 ou 4 alunos, distribua a atividade, uma para cada aluno, solicite que seja feita uma leitura coletiva, a fim de conhecer o contexto do problema. Oriente-os a fazer nova leitura em grupo, incentive os a fazer uma discussão sobre a possível solução, solicite que façam anotações referentes a solução, enquanto isso é indicado que o 
DOI:10.33238/ReBECEM.2020.v.4.n.3.25262

professor observe e acompanhe o desenvolvimento de cada grupo. Esteja atento para dificuldades, possíveis erros, capacidade de raciocínio lógico, pois esses aspectos contribuirão no próximo passo da aula, que é a discussão das soluções da atividade, onde ao considerar esses aspectos o docente consegue identificar se será preciso fazer adaptações ou não acerca da linguagem empregada. Por exemplo, mesmo com nível de oratória voltado para o aluno, às vezes é necessário facilitar ainda mais o processo de comunicação, devido a alguns agravantes relacionados a aprendizagem cognitiva dos alunos, não observados anteriormente.

Figura 2: Slide da atividade principal

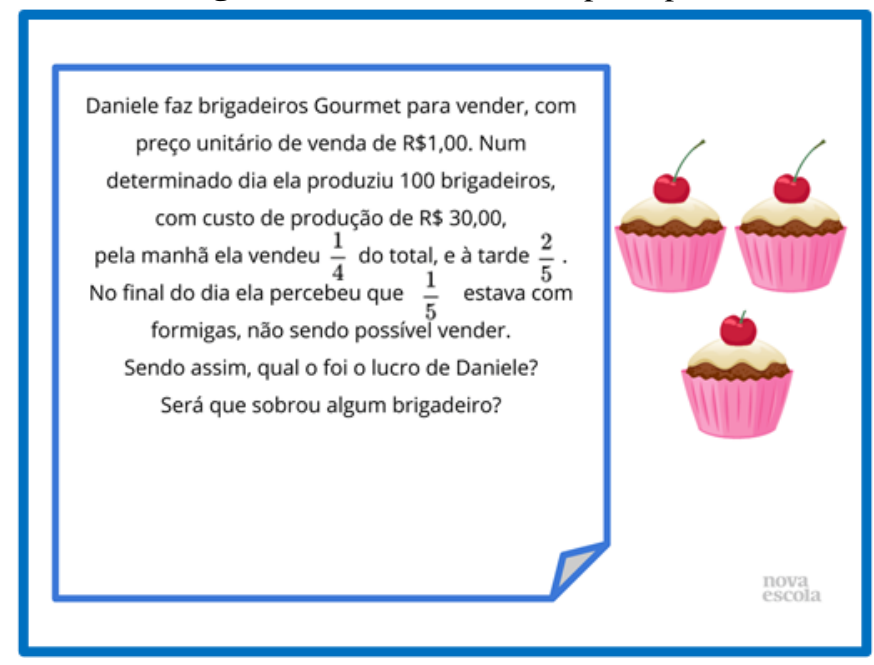

Fonte: Nova Escola (2018)

No quarto, quinto e sexto slide (discussão das soluções), apresentadas nas figuras 2, 3 e 4, respectivamente, possuem tempo sugerido de 14 minutos, têm o propósito de promover uma discussão sobre os resultados. É orientado ao professor verificar como os alunos chegaram às quantidades referente aos racionais informados na atividade, bem como a relação do numerador e denominador com os dados do exercício, a fim de chegar aos valores corretos correspondentes a cada parte. É indicado ainda discutir com a turma as seguintes perguntas: conseguem compreender a relação do numerador e denominador com a quantidade total? Por que vocês acham que um quarto, por exemplo, equivale a 25 brigadeiros? Como é possível? Por que somar a parte que está com formigas à parte que foi vendida? A parte que sobrou pode ser vendida? O lucro de Daniele poderia ser maior? Como seria possível? (Importante enfatizar que a parte com formigas sobrou, mas não pode ser vendida). 
DOI:10.33238/ReBECEM.2020.v.4.n.3.25262

Figura 3: Primeiro slide de discussão das soluções

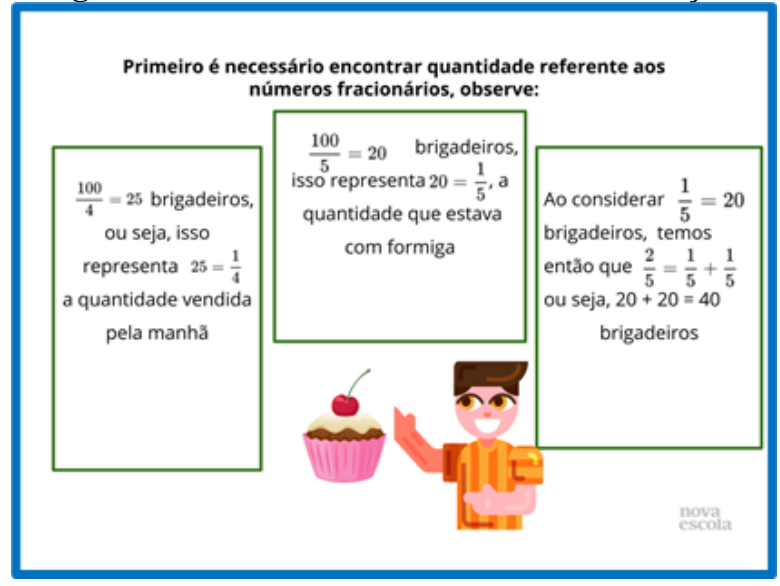

Fonte: Nova Escola (2018)

Figura 4: Segundo slide de discussão das soluções

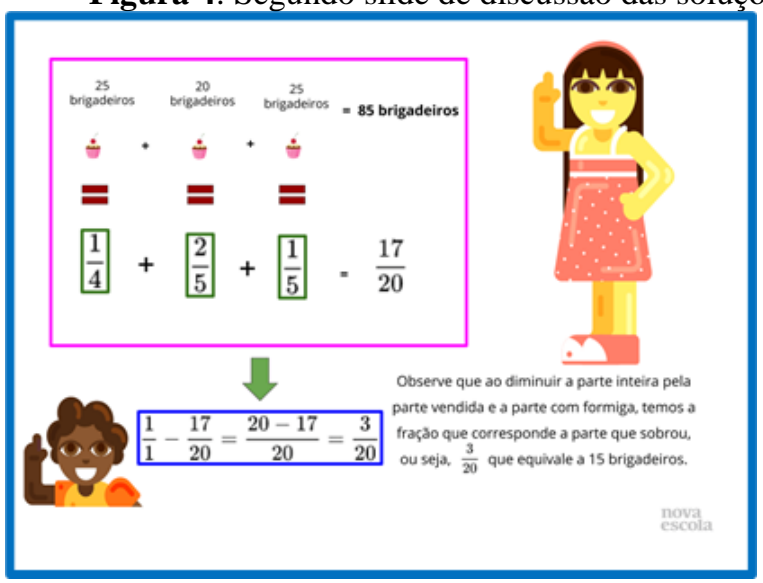

Fonte: Nova Escola (2018)

Figura 5: Terceiro slide de discussão das soluções

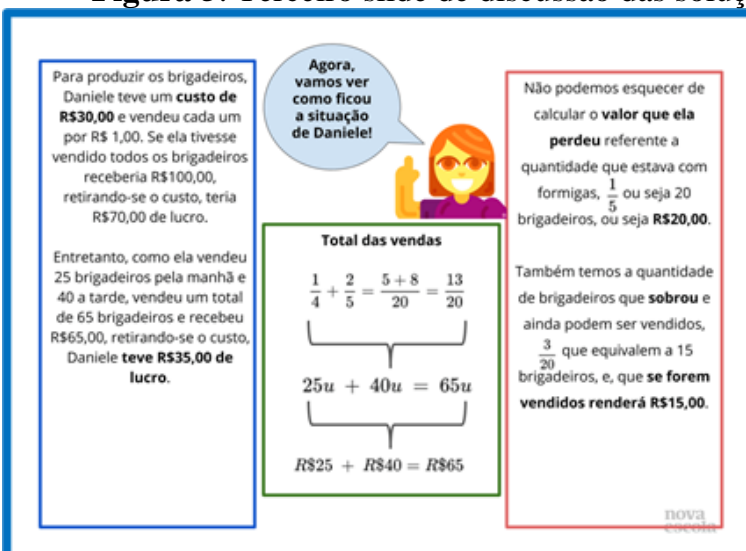

Fonte: Nova Escola (2018)

No sétimo slide (encerramento) apresentado na figura 6, com tempo sugerido de 2 minutos, é apresentado o resumo da aprendizagem, onde o professor é orientado a 
DOI:10.33238/ReBECEM.2020.v.4.n.3.25262

encerrar a aula retomando o objetivo da aula, junto com os alunos, a fim de concluir a presença da adição e subtração durante a aula, onde foi relacionada a quantidade unitária e valores monetários e sugerido realizar as perguntas: conseguiu perceber o objetivo de aprendizagem durante execução da atividade? Como você avalia o lucro de Daniele? Quais dicas você daria para prevenir futuras perdas?

Figura 6: Slide de encerramento

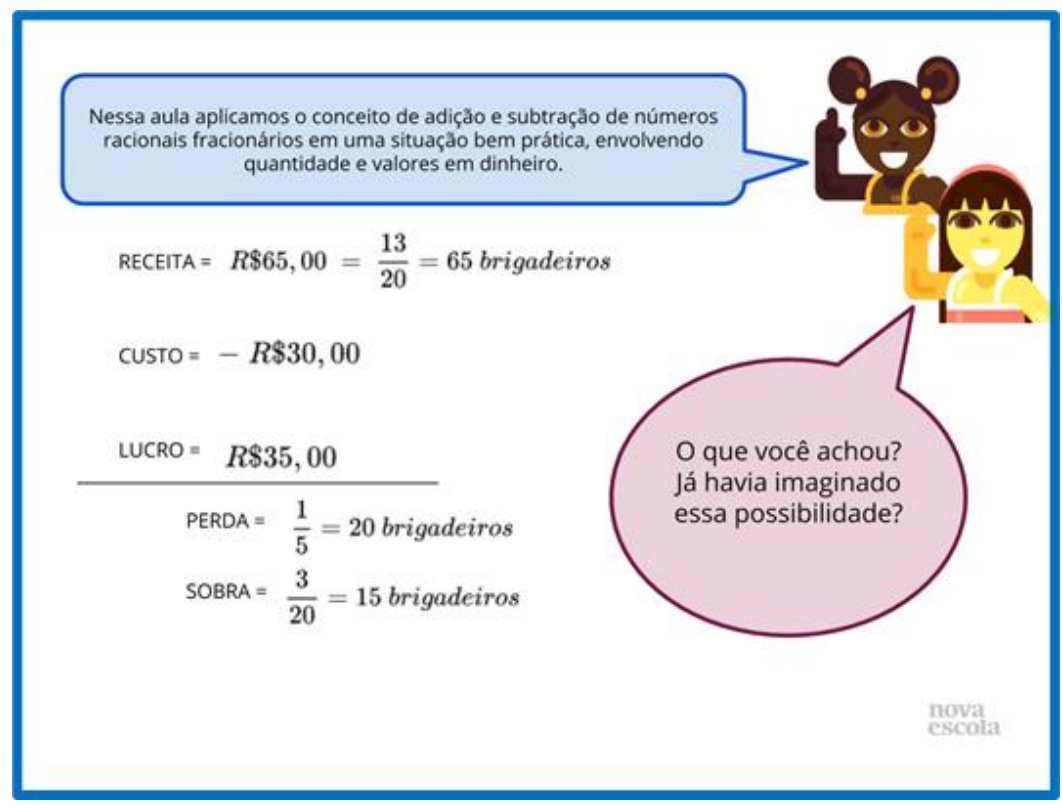

Fonte: Nova Escola (2018)

No oitavo e último slide (raio $\mathrm{x}$ ) apresentado na figura 7, com tempo sugerido de 6 minutos, é apresentada a atividade de raio x, com o propósito de avaliar se os alunos conseguem efetuar adição e subtração de racionais fracionários em situações contextualizadas. É sugerido ao professor, que a atividade seja realizada individualmente. Nesse momento, o professor verificará a aprendizagem do aluno, ou seja, é possível identificar se o estudante adquiriu ou não as habilidades esperadas dentro do conteúdo. Como sugestão, o ideal é separar alguns minutos para efetuar correção, a fim de que seja feita a verificação de possíveis erros. Ainda é indicado discutir com a turma as seguintes perguntas: quantos gramas de queijo você acha que cada um comeu a partir da quantidade expressa em forma de fração? Será que ficou muito ou pouco queijo para D. Sonia? Seria possível representar em forma de fração? Qual seria essa fração? 
Figura 7: Slide de raio $\mathrm{X}$

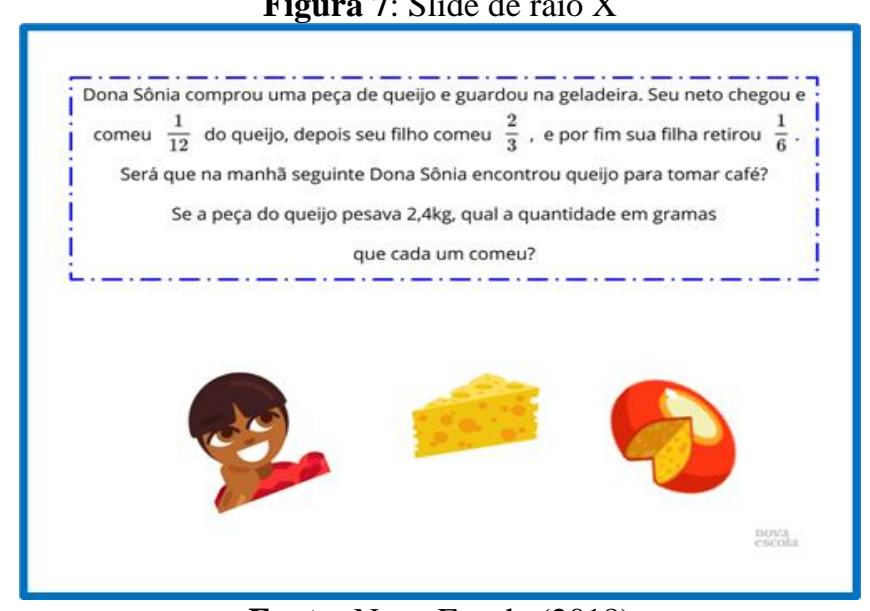

Fonte: Nova Escola (2018)

Além da produção de slides, também foram elaborados outros documentos de apoio ao planejamento e aplicação da aula, sendo eles a descrição das atividades (aquecimento ou retomada, atividade principal e raio $\mathrm{x}$ ) em formato para impressão para o aluno, bem como a descrição da mesma com resolução destinada ao professor. Além dessas, também foi elaborada atividade complementar, versão impressão para o aluno e versão com resolução para o professor, a fim de contribuir com a prática do professor em turma caso tenha algum aluno que realize as atividades com sucesso em menor tempo, assim essa atividade é indicada, sem impedir que o professor faça adaptação na utilização da mesma.

Destinado ao professor foi elaborado o guia de intervenção, com objetivo de abordar possíveis dificuldades e erros dos alunos em relação ao conteúdo na realização das atividades. Essa identificação é realizada por meio de perguntas que possam levar o aluno à reflexão, ou seja, são apresentados encaminhamentos que colaboram com o avanço dos estudantes. Por exemplo, nesse plano de ampliação, adição e subtração de racionais, foi sugerido como proposta referente à possível dificuldade do aluno em não recordar como efetuar a adição e/ou subtração de racionais fracionários e/ou em não conseguir efetuar o Mínimo Múltiplo Comum (MMC), nesse caso, a intervenção sugerida foi por meio da realização da pergunta "o que fazer quando temos denominadores diferentes?". Com isso, espera-se contribuir com a reflexão da necessidade do MMC para denominadores distintos ou frações equivalentes a fim de obter um denominador comum para a realização da adição ou da subtração. Quanto aos possíveis erros, também são sugeridas intervenções, por exemplo, referente ao possível erro no cálculo do lucro, é indicada a realização da seguinte pergunta "qual a fração corresponde ao prejuízo causado 
DOI:10.33238/ReBECEM.2020.v.4.n.3.25262

pelas formigas? Ela está incluída na fração 17/20?”. É esperado que o aluno perceba que o lucro de Daniele será calculado somente referente a parte vendida, e que, precisamos retirar a fração da perda que ocorreu devido às formigas isto é, $\frac{17}{20}-\frac{1}{5}=\frac{17-4}{20}=\frac{13}{20}$. No final da aula, é sugerido a realização deum momento de reflexão, a fim de obter a percepção dos alunos sobre a aula podendo ser por meio de pergunta. No caso específico do plano, no final da aula, a pergunta norteadora da reflexão foi "O que mais chamou sua atenção durante a aula?".

Ao considerar os estudos de Boaler (2018), a elaboração dos planos de aula, e disposição dos conteúdos observa-se que são utilizadas algumas estratégias denominadas de equitativas pela autora, que tem o foco em tornar a disciplina mais inclusiva. São considerados alguns pontos, como oferecer conteúdo de alto nível a todos os alunos, incentivar os estudantes a pensar profundamente sobre Matemática, a partir de experiências práticas, de um currículo baseado em projetos com aplicações na vida real, bem como a oportunidade de trabalhar colaborativamente.

Quando observamos a intervenção, a mediação docente durante o processo de ensino-aprendizagem por meio da realização de perguntas, observamos que são estabelecidas normas positivas intrínsecas ao denominado esforço produtivo, sendo que este é considerado como um processo cognitivo, que incentiva a aprendizagem dos alunos a partir de suas próprias ações, do seu próprio esforço. De acordo com Boaler (2018, p.240) “[...] todo aluno pode aprender Matemática nos níveis mais altos, voltado ao desenvolvimento de uma mentalidade de crescimento", relacionada ao aspecto de acreditar na capacidade de aprendizagem, fator que contribui positivamente para o desenvolvimento cognitivo do aluno. Os erros são considerados valiosos, pois é entendido que quando o aluno erra determinada solução, é possível que ele reflita, contextualize o percurso para se chegar até onde chegou, e o fato de errar deixa de ser algo negativo e bloqueador durante a aprendizagem. As perguntas são consideradas realmente importantes, pois a partir delas é proporcionado ao aluno uma série de descobertas a partir de situações que envolvem a interpretação e resolução de problemas.

Quando o esforço produtivo é considerado no planejamento de aula, é importante que aspectos referentes a avaliação sejam considerados, ou seja, entende-se que a mesma é realizada como estratégia de ensino, sob a ótica de uma avaliação formativa ligada ao efetivo rendimento dos estudantes de maneira efetiva. A partir dessa interpretação, a Matemática é vista como ciência que envolve conexões e comunicação, uma vez que 
DOI:10.33238/ReBECEM.2020.v.4.n.3.25262

Boaler (2018, p.247) considera que perguntas são realmente importantes, e ainda que a Matemática tem sua essência, “[...] a visualização de padrões e a criação de modos de solução que outros possam ver, discutir e criticar”.

Compreendemos que a referida abordagem tem relação com a ideia contextualizada na teoria de Vygotsky et al (1988) que considera que a verdadeira aprendizagem ocorre quando os alunos estão diante de novas ideias, esforçando assim para encaixar nos seus modelos, resultando em uma verdadeira aprendizagem, aspecto que está intrinsecamente ligado ao processo da dialética. Já Smith et al. (2000), identifica que o processo do esforço produtivo exige do aluno considerável esforço cognitivo, contribuindo assim para possíveis soluções.

Contudo, os planos de aula de Matemática do projeto, bem como de outras disciplinas que estão no cronograma de elaboração, foram desenvolvidos com apoio e orientação pedagógica, de área específica e tecnológica, referente à estrutura, disposição de conteúdo, design de material destinado ao aluno e outros fatores indispensáveis no processo de planejamento de aulas. O plano apresentado neste trabalho, bem como outros que englobam todas as séries do Ensino Fundamental, referente às unidades temáticas descritas na Base Nacional Comum Curricular, podem ser acessados no site da revista "Nova Escola".

\section{Considerações finais}

Exercer à docência no ensino de Matemática com um olhar diferenciado em um país que possui dados insatisfatórios referentes a avaliação da aprendizagem da mesma, é um desafio. Dentre eles, encontramos a precarização da estrutura física do ambiente escolar, a superlotação de alunos por sala, bem como aspectos relacionados à baixa perspectiva dos alunos quanto à disciplina, ligados a aspectos motivacionais, a ausência ou baixa qualidade de capacitação e do aprimoramento docente. Assim, compreende-se que esses aspectos interferem negativamente no processo de ensino-aprendizagem, fazendo-se necessário trilhar caminhos norteadores da concretização de uma prática com foco no desenvolvimento de habilidades, por meio de uma metodologia diferenciada. Durante a pesquisa, foi identificado que metodologia diferenciada no contexto do ensino de Matemática com foco em um planejamento da ação didática, permitiu uma prática idealizadora, por meio da fixação de objetivos. 
DOI:10.33238/ReBECEM.2020.v.4.n.3.25262

A partir de experiência docente e descrição do nosso objetivo geral deste estudo, que visa uma análise pedagógica a partir da utilização dos planos de aula "Nova Escola", percebe-se que a fixação de um planejamento no processo de ensino-aprendizagem por meio da escolha adequada da metodologia e do material utilizado em sala de aula, contribui com o desenvolvimento de mentalidades em crescimento descrito por Boaler (2018), ou seja, a partir da utilização de atividades diferenciadas, é proporcionado ao aluno uma aprendizagem onde suas ações o caracterizam como protagonistas, engajados numa aprendizagem profunda, sem desconsiderar a mediação docente, por meio de um processo ativo.

Ao considerarmos os pressupostos dos objetivos específicos, compreendemos que a reflexão da metodologia contida nos planos, favorece o planejamento docente, o aprendizado do aluno e proporciona ao professor um apoio didático na elaboração do seu planejamento de aula, sendo possível inserir ou caracterizar aspectos típicos do jeito de ser docente, de realizar a sua prática em sala no cotidiano. Assim, identificamos a viabilidade em realizar prática docente sob a ótica de intervenção pedagógica intrínseca a dificuldade do aluno, com foco na análise do processo de ensino-aprendizado e relação de utilização de material didático.

Ao considerar a proposta inicial, esperamos que a descrição do processo de planejamento realizado por meio dos planos de aula "Nova Escola" possa favorecer o processo de construção do planejamento de professores em sua prática cotidiana, e assim contribuir com o fortalecimento de uma educação pública de qualidade, com foco inclusivo de englobar todos os alunos das diferentes realidades escolares do nosso país.

Ao concluir a descrição deste estudo tivemos a oportunidade de repensar, modificar e constituir nossa prática. Foi uma oportunidade de constituir um novo olhar sobre as vertentes e desafios ligados à proposta curricular aliada ao modelo de ensino ativo. A reflexão foi feita numa perspectiva de contribuir com o compartilhamento de experiência e prática, a fim de ampliar um novo olhar sobre o ensino de Matemática e estudos nessa linha de análise. Importante destacar que a revisitação de práticas por meio da formação continuada, permite aos indivíduos a constituição, pois é possível considerar que a construção do conhecimento é contínua e não para. Contudo, destaca-se que nesse estudo, foram identificadas outras questões que motivaram a realização de análises mais amplas que não foi possível aprofundar, pois afinal o processo é contínuo. 
DOI:10.33238/ReBECEM.2020.v.4.n.3.25262

Dessa maneira, agradecemos a leitura acompanhada de análise, espera-se que esse trabalho enriqueça o processo de estudo e elaboração do planejamento docente dos professores em sua prática cotidiana e contribua com a fixação de metodologias diferenciadas e acessíveis às diversas realidades do ensino da escola brasileira.

\section{Referências}

BRASIL. Base Nacional Comum Curricular. 2017. Disponível em: <http://basenacionalcomum.mec.gov.br/>. Acesso em: 04 mai. 2020.

BRASIL. Ministério da Educação. Parâmetros Curriculares Nacionais: introdução aos Parâmetros Curriculares Nacionais. Brasília, DF: MEC, 1997.

BOALER, Jo. Mentalidades Matemáticas: estimulando o potencial dos estudantes por meio da matemática criativa, das mensagens inspirados e do ensino inovador/Jo Boaler; tradução: Daniel Bueno; revisão técnica: Fernando Amaral Carnaúba, Isabele Veronese, Patrícia Cândido. - Porto Alegre: Penso, 2018.

D’AMBROSIO, U. Educação Matemática: Da teoria à prática. Campinas: Papirus, 1996.

DARC, L. Afinal, o que é esforço produtivo e como ele funciona na Matemática? 2017. Disponível em: <https://novaescola.org.br/conteudo/7090/afinal-o-que-e-esforco-produtivo-ecomo-ele-funciona-na-matematica>. Acesso em: 05 mai .2020.

HAYDT, R. C. C. O Planejamento da ação didática. 8. ed. São Paulo: Ática, 2006.

INEP. Programa Internacional de Avaliação de Estudantes - PISA. 2019. Disponível em: <http://inep.gov.br/web/guest/pisa>. Acesso em: 01 abr. 2020.

LIBÂNEO, J. C. Didática. São Paulo: Cortez editora, 2006.

LIMA, A. A.; COELHO, R. R. C.; SILVA, R. C. da. A importância do trabalho diferenciado dentro da disciplina de Matemática no Ensino Fundamental. Revista de Pesquisa Interdisciplinar, Cajazeiras, v. 1, Ed. Especial, p. 564 - 572, set/dez., 2016.

NOVA ESCOLA. Projeto Planos de aula em Matemática: Adição e subtração de racionais na forma fracionária (ampliação). 2018. Revista NOVA ESCOLA. Disponível em: $<$ https://novaescola.org.br/plano-de-aula/1954/adicao-e-subtracao-de-racionais-fracionarios-napratica-ampliacao>. Acesso em: 31 mar. 2020. 
DOI:10.33238/ReBECEM.2020.v.4.n.3.25262

NOVA ESCOLA. Sobre os planos de aula. 2017. Disponível em: <https://novaescola.org.br/plano-de-aula/sobre>. Acesso em: 31 mar. 2020.

SMITH, M. S.; SILVER, E. S.; STEIN, M. K. Implementing standards-based mathematics instruction: A casebook for professional development. New York: Teachers College Press. 2000, p. 16.

VEIGA, I. P. A. Organização Didática da aula: um projeto colaborativo de ação imediata. In: VEIGA, I. P. A (Org). Aula: gênese, dimensões, princípios e práticas. Campinas: Papirus, 2008, p. 267-297.

LEONTIEV, A. N.; LURIA, A.R.; VYGOTSKY, L.S. Linguagem, desenvolvimento e aprendizagem. São Paulo: Ícone/Edusp, 1988.

YIN, R. K. Estudo de caso: planejamento e métodos. Daniel Grassi (Trad). 2.ed. Porto Alegre: Bookman, 2001.

Recebido em: 19 de junho de 2020

Aceito em: 27 de julho de 2020 